\title{
Lidar detection of carbon dioxide in volcanic plumes
}

\author{
Luca Fiorani $^{* a}$, Simone Santoro ${ }^{\text {bc }}$, Stefano Parracino ${ }^{\mathrm{dc}}$, Giovanni Maio ${ }^{\mathrm{ec}}$, Mario Del Franco ${ }^{\mathrm{f}}$, \\ Alessandro Aiuppa ${ }^{\mathrm{b}}$ \\ ${ }^{a}$ Diagnostics and Metrology Laboratory, ENEA, Via Enrico Fermi 45, 00044 Frascati, Italy; \\ ${ }^{b}$ Department of Earth and Sea Sciences, University of Palermo, Via Archirafi 36, 90123 Palermo, \\ Italy; 'ENEA guest; ${ }^{\mathrm{d}}$ Department of Industrial Engineering, University of Rome "Tor Vergata", Via \\ del Politecnico 1, 00133 Rome, Italy; 'ARES Consortium, c/o University of Rome "Tor Vergata",

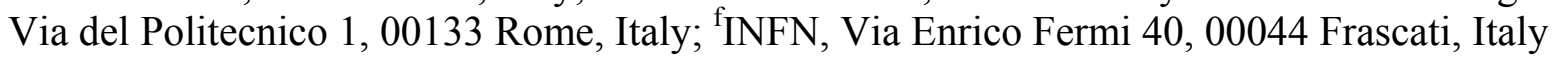

\begin{abstract}
Volcanic gases give information on magmatic processes. In particular, anomalous releases of carbon dioxide precede volcanic eruptions. Up to now, this gas has been measured in volcanic plumes with conventional measurements that imply the severe risks of local sampling and can last many hours. For these reasons and for the great advantages of laser sensing, the thorough development of volcanic lidar has been undertaken at the Diagnostics and Metrology Laboratory (UTAPRAD-DIM) of the Italian National Agency for New Technologies, Energy and Sustainable Economic Development (ENEA). In fact, lidar profiling allows one to scan remotely volcanic plumes in a fast and continuous way, and with high spatial and temporal resolution. Two differential absorption lidar instruments will be presented in this paper: BILLI (BrIdge voLcanic LIdar), based on injection seeded Nd:YAG laser, double grating dye laser, difference frequency mixing (DFM) and optical parametric amplifier (OPA), and VULLI (VULcamed Lidar), based on injection seeded Nd:YAG laser and optical parametric oscillator (OPO). The first one is funded by the ERC (European Research Council) project BRIDGE and the second one by the ERDF (European Regional Development Fund) project VULCAMED. While VULLI has not yet been tested in a volcanic site, BILLI scanned the gas emitted by Pozzuoli Solfatara (Campi Flegrei volcanic area, Naples, Italy) during a field campaign carried out from 13 to 17 October 2014. Carbon dioxide concentration maps were retrieved remotely in few minutes in the crater area. Lidar measurements were in good agreement with well-established techniques, based on different operating principles. To our knowledge, it is the first time that carbon dioxide in a volcanic plume is retrieved by lidar, representing the first direct measurement of this kind ever performed on an active volcano and showing the high potential of laser remote sensing in geophysical research.
\end{abstract}

Keywords: laser remote sensing, differential absorption lidar, gas detection, volcanic phenomena

\section{INTRODUCTION}

Ten active volcanos ${ }^{1}$ and many dormant volcanos are located in central and Southern Italy. Their craters are often very close to densely populated urban areas. In order to assess the potential risks, Italian Civil Protection National Service (DPC) supports continuous monitoring and restricts the access to dangerous zones. In this framework, the Diagnostics and Metrology Laboratory (UTAPRAD-DIM) of the Frascati Research Center of the Italian National Agency for New Technologies, Energy and Sustainable Economic Development (ENEA) carries out research on differential absorption lidar (DIAL) ${ }^{2}$ of carbon dioxide in volcanic plumes. Carbon dioxide has been chosen because its anomalous release has been shown to anticipate volcanic eruptions ${ }^{3}$.

Two systems are under development: BrIdge voLcanic LIdar (BILLI) ${ }^{4}$, funded by the ERC (European Research Council) project BRIDGE, and VULcamed Lidar (VULLI) funded by the ERDF (European Regional Development Fund) project VULCAMED. The first one is based on injection seeded Nd:YAG laser, double grating dye laser, difference frequency mixing (DFM) and optical parametric amplifier (OPA), and the second one relies on injection seeded Nd:YAG laser and optical parametric oscillator (OPO).

*luca.fiorani@enea.it; phone 3906 9400-5861; fax 3906 9400-5312; www.enea.it

Third International Conference on Remote Sensing and Geoinformation of the Environment (RSCy2015), edited by Diofantos G. Hadjimitsis, Kyriacos Themistocleous, Silas Michaelides, Giorgos Papadavid,

Proc. of SPIE Vol. 9535, 95350N · () 2015 SPIE · CCC code: 0277-786X/15/\$18 · doi: 10.1117/12.2192724

Proc. of SPIE Vol. 953595350 N-1 
BILLI has been mounted in a small truck and carried out the 3D profiling of the volcanic plume of Pozzuoli Solfatara in October $2014^{5}$. It is the first time that carbon dioxide in a volcanic plume is retrieved by lidar, although laser remote sensing has already been applied to sound aerosol load ${ }^{6}$, sulfur dioxide ${ }^{7}$ and water vapor ${ }^{8}$ in volcanic plumes: up to now, to our knowledge, lidar soundings of $\mathrm{CO}_{2}$ have been performed, but not in volcanic plumes ${ }^{9}$, and differential absorption measurements of volcanic $\mathrm{CO}_{2}$ have been carried out, but they were not range resolved ${ }^{10}$. VULLI underwent a first test at the end of 2014, is under upgrade at UTAPRAD-DIM and it is expected to operate in a volcanic area within 2015. BILLI and VULLI can also be used for the measurement of wind speed ${ }^{8}$, thanks to their ability of aiming the laser beam in different directions. The main specifications of the two DIAL systems are listed on Table 1.

Table 1. Main specifications of the two DIAL systems.

\begin{tabular}{|c|c|c|c|}
\hline DIAL system & & BILLI & VULLI \\
\hline \multirow{6}{*}{ Transmitter } & Pulse energy & $25 \mathrm{~mJ}$ & $17(2014), 25(2015) \mathrm{mJ}$ \\
\hline & Pulse duration & $8 \mathrm{~ns}$ & $<6 \mathrm{~ns}$ \\
\hline & Repetition rate & $10 \mathrm{~Hz}$ & $10 \mathrm{~Hz}$ \\
\hline & Wavelengths & $1.6,2.1 \mu \mathrm{m}$ & $1.57-2.08(2014), 1.5-3.4(2015) \mu \mathrm{m}$ \\
\hline & Laser linewidth & $0.04 \mathrm{~cm}^{-1}$ & $0.15(2014), 0.02(2015) \mathrm{cm}^{-1}$ \\
\hline & Beam divergence & $0.5 \mathrm{mrad}$ & $2(2014), 0.5(2015) \mathrm{mrad}$ \\
\hline \multirow{3}{*}{ Receiver } & Mirror coating & $\mathrm{Al}$ & $\mathrm{Al}$ \\
\hline & Clear aperture & $300 \mathrm{~mm}$ & $300 \mathrm{~mm}$ \\
\hline & Focal length & $900 \mathrm{~mm}$ & $1200 \mathrm{~mm}$ \\
\hline \multirow{6}{*}{ Detector module } & Photodiode & InGaAs PIN & InGaAs PIN \\
\hline & Diameter & $1 \mathrm{~mm}$ & $1 \mathrm{~mm}$ \\
\hline & Responsivity & $1.2 \mathrm{~A} \mathrm{~W}^{-1}$ & $1.2 \mathrm{~A} \mathrm{~W}^{-1}$ \\
\hline & Gain & $5.1 \times 10^{4} \mathrm{~V} \mathrm{~A}^{-1}$ & $5.1 \times 10^{4} \mathrm{~V} \mathrm{~A}^{-1}$ \\
\hline & Noise equivalent power & $10 \mathrm{pW} \mathrm{Hz}^{-1 / 2}$ & $10 \mathrm{pW} \mathrm{Hz}^{-1 / 2}$ \\
\hline & Bandwidth & $0 \div 10 \mathrm{MHz}$ & $0 \div 10 \mathrm{MHz}$ \\
\hline \multirow{2}{*}{ Analog-to-digital converter (ADC) } & Dynamic range & 14 bit & 14 bit \\
\hline & Sampling rate & $100 \mathrm{MS} \mathrm{s}^{-1}$ & $100 \mathrm{MS} \mathrm{s}^{-1}$ \\
\hline
\end{tabular}

$\mathrm{CO}_{2}$ absorbs in the 15, 4.2, 2.1 and $1.6 \mu \mathrm{m}$ bands (in order of decreasing strength) ${ }^{11}$. Unfortunately, in the first two bands viable lasers are not available and atmospheric backscattering is rather low, so the 2.1 and $1.6 \mu \mathrm{m}$ bands have been suggested for its detection ${ }^{12}$. Nevertheless, the DIAL measurement of $\mathrm{CO}_{2}$ remains a difficult task because the absorption lines are narrow and weak ${ }^{13}$.

As powerful, tunable and narrow-linewidth laser source we chose:

- a dye laser with difference frequency mixing (DFM) and optical parametric amplifier (OPA) for BILLI,

- an optical parametric oscillator (OPO) for VULLI.

Tm,Ho:YLF and fiber lasers have been discarded ${ }^{4}$ mainly for their limited tunability (few tenths of nm) that can prevent to choose the best absorption line ${ }^{14}$.

\section{BILLI (BRIDGE VOLCANIC LIDAR)}

From 13 to 17 October 2014, BILLI measured carbon dioxide inside the volcanic plume of Pozzuoli Solfatara in Contrada Pisciarelli (Campi Flegrei crater area, Naples, Italy) ${ }^{5}$. Lidar retrievals were in good agreement with

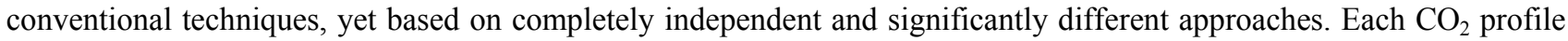
was obtained averaging 200 lidar returns at $10 \mathrm{~Hz}$, corresponding to a temporal resolution of $20 \mathrm{~s}$. The spatial resolution was $1.5 \mathrm{~m}$. A total plume scan was retrieved combining 20-30 profiles, i.e. in less than 10 minutes. 

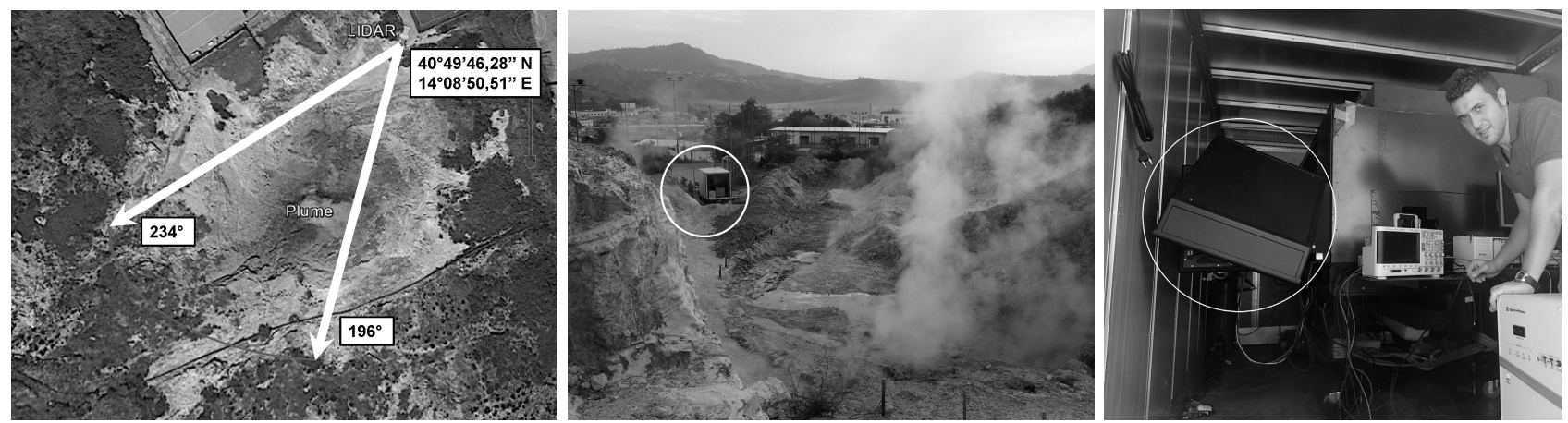

Figure 1. Left) Location of lidar and plume, and most northern/southern directions of the laser beam during the measurements. Center) Volcanic plume emitted by the Pozzuoli Solfatara in Contrada Pisciarelli. The lidar is mounted in a small truck (inside the white circle). Right) Lidar inside the truck. The laser beam is aimed by two large elliptical mirrors (major axis: $450 \mathrm{~mm}$ ) mounted in two black boxes (inside the white circle).

BILLI was located at latitude $40^{\circ} 49^{\prime} 46.28^{\prime \prime} \mathrm{N}$ and longitude $14^{\circ} 08^{\prime} 50.51^{\prime \prime} \mathrm{E}$ (Figure 1), and the laser beam scanned typically the heading angles from $196^{\circ}$ to $234^{\circ}$ at an elevation from $0^{\circ}$ to $18^{\circ}$. The laser beam was backscattered by the plume and by the rockface (Figure 2). Each lidar return can be divided into two portions, one inside the plume and another outside it, where the $\mathrm{CO}_{2}$ concentrations equal to the natural background $\left(\mathrm{C}_{0}=400 \mathrm{ppm}\right)$. This latter includes two segments, respectively before (length: $\mathrm{L}_{1}$ ) and after (length: $\mathrm{L}_{2}$ ) the plume interception. Assuming that inside the plume the $\mathrm{CO}_{2}$ concentration corresponding to the $\mathrm{i}$-th $\mathrm{ADC}$ channel $\left(\mathrm{C}_{\mathrm{i}}\right)$, is proportional to the lidar signal in the $\mathrm{i}$-th ADC channel $\left(\mathrm{S}_{\mathrm{i}}\right)$, the optical depth of the laser path can be written as:

$$
O D=\Delta \sigma\left[C_{0}\left(L_{1}+L_{2}\right)+\Delta R k \sum_{i} S_{i}\right]
$$

where $\Delta \sigma$ is the $\mathrm{CO}_{2}$ differential absorption cross section and $\mathrm{k}$ is the proportionality constant between $\mathrm{C}_{\mathrm{i}}$ and $\mathrm{S}_{\mathrm{i}}$. The proportionality assumption is very reasonable because the light backscattering is due to aerosol that is dominated by water droplets, and $\mathrm{H}_{2} \mathrm{O}$ and $\mathrm{CO}_{2}$ are usually proportional in volcanic plumes.

OD can be measured as follows:

$$
O D=\ln \left[\frac{S_{R}\left(\lambda_{O F F}\right) / S_{L}\left(\lambda_{O F F}\right)}{S_{R}\left(\lambda_{O N}\right) / S_{L}\left(\lambda_{O N}\right)}\right],
$$

where $S_{R}$ is the lidar signal from the rockface, $S_{L}$ is the signal due to the scattering, inside the laboratory, of some photons of the transmitted laser pulse (this peak gives the exact time of pulse transmission and is proportional to the transmitted energy, thus providing the signal normalization) and $\lambda_{\mathrm{ON}} / \lambda_{\mathrm{OFF}}$ is the more/less absorbed wavelength used in the DIAL experiment.
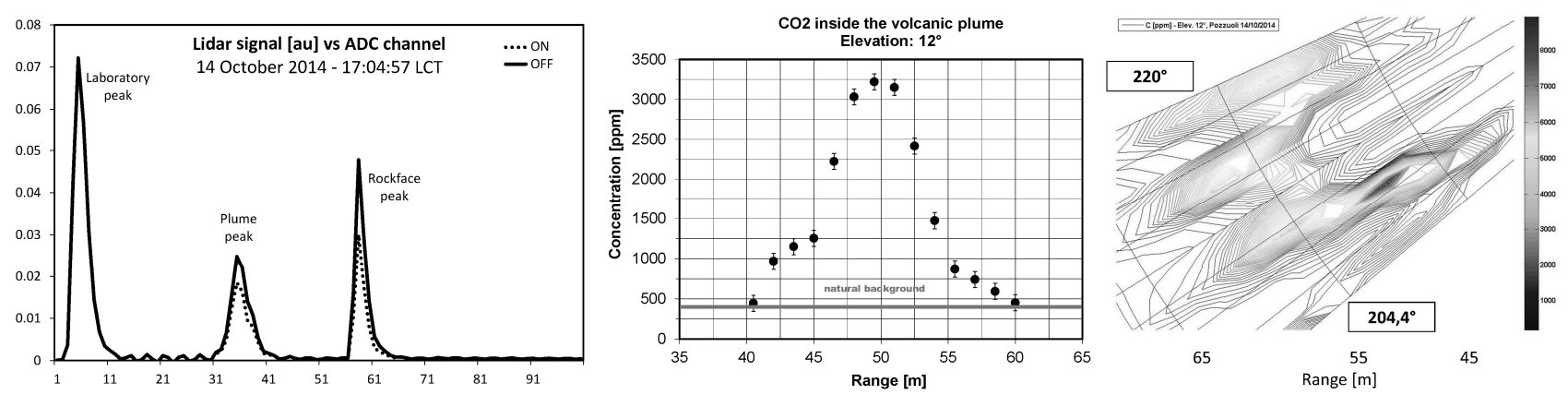

Figure 2. Example of: Left) lidar signal. Center) $\mathrm{CO}_{2}$ profile. Right) Plume scan (the vent correspond to the grey spot). 
Once determined $\mathrm{OD}$, equation (1) can be solved for $\mathrm{k}$, the only remaining unknown, and $\mathrm{C}_{\mathrm{i}}$ can be simply calculated as the product of $k$ and $S_{i}$ (Figure 2). Sometimes, the plume was so optically thick that the rockface was not detected. In this case, in equation (2) the signal peak due to the plume was used instead of that due to the rockface, and carbon dioxide was retrieved only before the peak due to the plume, applying equation (1) with $\mathrm{L}_{2}=0$.

The measurement error was dominated by inaccuracy in wavelength setting. This is why, back to the Frascati Research Center, we implemented a photo-acoustic cell filled with pure $\mathrm{CO}_{2}$ at atmospheric pressure and temperature, close to the laser exit, as shown in figure 3. Using new software developed for this application, we are able to change the transmitted wavelength (by moving the stepper motor inside the resonator cavity of the dye laser) and to record the photo-acoustic signal (averaging 10 laser shots, corresponding to $1 \mathrm{~s}$ ). Once corrected the wavelength for a small shift $\left(0.12 \mathrm{~cm}^{-1}\right)$, the agreement between experiment and theory ${ }^{13}$ is very good (figure 3 ).

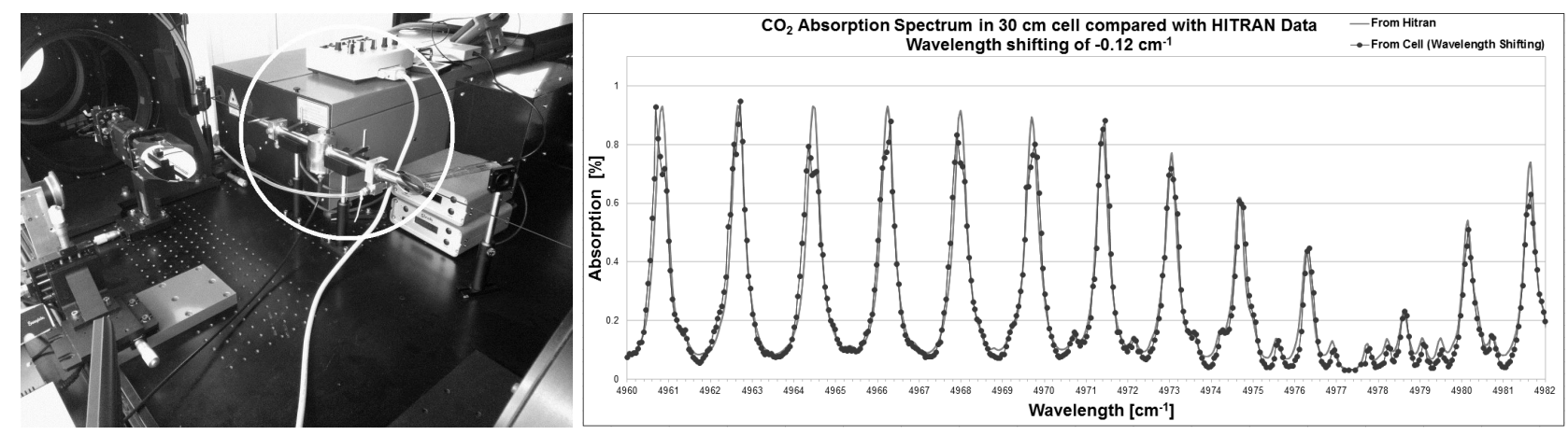

Figure 3. Left) Photo-acoustic cell (inside the white circle). Right) Theoretical (line) and experimental (circles and line) $\mathrm{CO}_{2}$ absorption spectrum.

\section{VULLI (VULCAMED LIDAR)}

A first version of VULLI has been completed in 2014 (figure 4). It reached the following specifications:

- spectral range $1.57-2.08 \mu \mathrm{m}$,

- linewidth $0.15 \mathrm{~cm}^{-1}$,

- power $170 \mathrm{~mW}$,

- pulse duration less than $6 \mathrm{~ns}$.
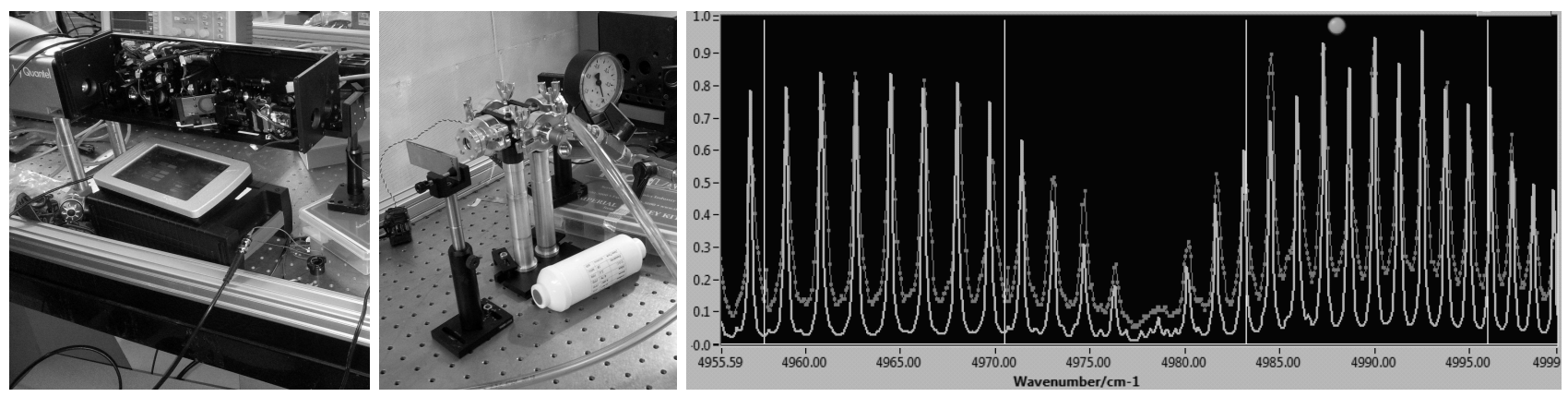

Figure 4. Left) The OPO opened during the test of the laser source of VULLI. Center) Photo-acoustic cell.

Right) Theoretical (line) and experimental (circles and line) $\mathrm{CO}_{2}$ absorption spectrum. 
The spectral purity of the laser source has been checked with a cell filled with $\mathrm{CO}_{2}$ (figure 4), equipped with a microphone to record the photo-acoustic absorption spectrum. Theoretical ${ }^{13}$ and experimental spectrum are in excellent agreement (figure 4), demonstrating that VULLI is ready to be tested on the field, with the purpose of measuring carbon dioxide in the atmosphere.

Notwithstanding these encouraging result, the system will be upgraded in 2015 , in order to reduce even more its linewidth, with the final goal of reaching a linewidth of $0.02 \mathrm{~cm}^{-1}$ (single longitudinal mode). Other specifications of VULLI will evolve as indicated in Table 1.

\section{CONCLUSIONS}

BILLI and VULLI, two differential absorption lidar for 3D profiling of carbon dioxide in volcanic plumes, are under development at the UTAPRAD-DIM laboratory of the Frascati Research Center of ENEA.

Both the laser sources developed for BILLI and VULLI are "single pieces", realized according to our specifications by world leading manufacturers: the great challenge was to realize laser sources transmitting very narrow linewidths and operating in the harsh environment characteristic of volcanic zones. Moreover, they must reach high power and emit nearly simultaneously two wavelengths. The source chosen for BILLI is more conservative: it is more reliable and has a better quality of the laser beam (circular profile, smaller size and lower divergence). On the contrary, the source chosen for VULLI requires still development, but is less complex, large, heavy and expensive. Our strategic choice, effective up to now, was to differentiate the technical approaches, in order to increase the probability of success of our volcanic activity: in fact BILLI carried out the first lidar measurement of carbon dioxide in a volcanic plume and VULLI promises to follow the example of his older brother.

\section{ACKNOWLEDGEMENTS}

The authors are grateful to R. Fantoni and A. Palucci for constant encouragement. They thank: L. Cannilla for procurement assistance; Sirah and Laser Optronic for the BILLI laser customization (P. Jauernik and S. De Pascalis) and installation (A. Wloka and P. Stropiccioli); LaserSpec and Crisel Instruments for the VULLI laser customization (G. Penco) and installation (A. Peremans); Marcon Telescopes (L. Marcon) for telescope elements; LAV Coatings (E. Giannelli) for telescope coatings; Hamamatsu (M. Aversa) for custom detectors; TSC (M. Cesarini) for mechanical parts. The support from the ERC project BRIDGE, n. 305377, and from the ERDF project VULCAMED, n. D11D11000080007, is gratefully acknowledged.

\section{REFERENCES}

[1] http://vulcani.ingv.it/en/

[2] L. Fiorani, "Lidar application to litosphere, hydrosphere and atmosphere," in Progress in Laser and ElectroOptics Research, V. V. Koslovskiy, ed., 21-75 (Nova, New York, 2010).

[3] A. Aiuppa, M. Burton, T. Caltabiano, G. Giudice, S. Guerrieri, M. Liuzzo, F. Murè, G. Salerno, "Unusually large magmatic $\mathrm{CO}_{2}$ gas emissions prior to a basaltic paroxysm," Geophys. Res. Lett. 37, paper L17303 - 5 pp. (2010).

[4] L. Fiorani, A. Aiuppa, F. Angelini, R. Borelli, M. Del Franco, D. Murra, M. Pistilli, A. Puiu, S. Santoro, "Lidar sounding of volcanic plumes," Proc. SPIE 8894, paper 7 - 10 pp. (2013).

[5] L. Fiorani, S. Santoro, S. Parracino, M. Nuvoli, C. Minopoli, A. Aiuppa, "Volcanic $\mathrm{CO}_{2}$ detection with a DFM/OPA-based lidar," Opt. Lett. 40, 1034-1036 (2015).

Early posting: http://www.opticsinfobase.org/ol/upcoming.cfm?page=7

[6] L. Fiorani, F. Colao, and A. Palucci, "Measurement of Mount Etna plume by $\mathrm{CO}_{2}$-laser-based lidar," Opt. Lett. 34, 800-802 (2009).

[7] P. Weibring, H. Edner, S. Svanberg, G. Cecchi, L. Pantani, R. Ferrara, and T. Caltabiano, "Monitoring of volcanic sulphur dioxide emissions using differential absorption lidar (DIAL), differential optical absorption spectroscopy (DOAS), and correlation spectroscopy (COSPEC)," Appl. Phys. B 67, 419-426 (1998).

[8] L. Fiorani, F. Colao, A. Palucci, D. Poreh, A. Aiuppa, and G. Giudice, "First-time lidar measurement of water vapor flux in a volcanic plume," Opt. Comm. 284, 1295-1298 (2011). 
[9] G. J. Koch, J. Y. Beyon, F. Gibert, B. W. Barnes, S. Ismail. M. Petros, P. J. Petzar, J. Yu, E. A. Modlin, K. J. Davis, and U. N. Singh, "Side-line tunable laser transmitter for differential absorption lidar measurements of $\mathrm{CO}_{2}$ : design and application to atmospheric measurements," Appl. Opt. 47, 944-956 (2008).

[10] Queißer M., Burton M., Fiorani L. "Differential absorption lidar for volcanic $\mathrm{CO}_{2}$ sensing tested in an unstable atmosphere," Opt. Express 23, 6634-6644 (2015).

[11]P. J. Linstrom and W. G. Mallard, "The NIST Chemistry WebBook: A Chemical Data Resource on the Internet", J. Chem. Eng. Data 46, 1059-1063 (2001).

[12]R. T. Menzies and D. M. Tratt, "Differential laser absorption spectrometry for global profiling of tropospheric carbon dioxide: selection of optimum sounding frequencies for high-precision measurements," Appl. Opt. 42, 6569-6577 (2003).

[13]L. S. Rothman, I. E. Gordon, A. Barbe, D. C. Benner, P. F. Bernath, M. Birk, V. Boudon, L. R. Brown, A. Campargue, J.-P. Champion, K. Chance, L. H. Coudert, V. Dana, V. M. Devi, S. Fally, J.-M. Flaud, R. R. Gamache, A. Goldman, D. Jacquemart, I. Kleiner, N. Lacome, W. J. Lafferty, J.-Y. Mandin, S. T. Massie, S. N. Mikhailenko, C. E. Miller, N. Moazzen-Ahmadi, O. V. Naumenko, A. V. Nikitin, J. Orphal, V. I. Perevalov, A. Perrin, A. Predoi-Cross, C. P. Rinsland, M. Rotger, M. Šimečková, M. A. H. Smith, K. Sung, S. A. Tashkun, J. Tennyson, R. A. Toth, A. C. Vandaele, and J. VanderAuwera, "The HITRAN 2008 molecular spectroscopic database," J. Quant. Spectrosc. Radiat. Transfer 110, 533-572 (2009).

[14]L. Fiorani, W. R. Saleh, M. Burton, A. Puiu, and M. Queißer, "Spectroscopic considerations on DIAL measurement of carbon dioxide in volcanic emissions," J. Optoelectron. Adv. M. 15, 317-325 (2013). 